\title{
LA CUESTIÓN ANIMAL: ENTRE LA REGULACIÓN DEL COMERCIO Y LA DESMERCANTILIZACIÓN DE LO VIVO
}

\author{
DABEL LEANDRO FRANCO \\ Becario de iniciación a la investigación \\ Colaborador del proyecto de investigación "Codex humano: normas, tecnologías y \\ programas para el gobierno de lo vivo" \\ Facultad de Ciencias Jurídicas y Sociales de la Universidad Nacional del Litoral \\ (Argentina) \\ dabel.leandro@gmail.com
}

Recibido: 27 de enero de 2016 / Aceptado: 3 de abril de 2016

RESUMEN: Este artículo tiene como objetivo caracterizar las distintas respuestas que se han elaborado frente al creciente comercio de animales no humanos y sus respectivas traducciones al campo jurídico, entre las cuales se han identificado, con fines analíticos, dos grandes programas: por una parte, la "protección mediante la regulación del comercio" y, por otra, la "protección mediante la desmercantilización de lo vivo". Desde esta perspectiva se analiza, en primer lugar, la Convención sobre el Comercio Internacional de Especies Amenazadas de Fauna y Flora Silvestres (CITES), lo cual permite presentar los elementos medulares del primer programa. Luego se indaga en torno a los aportes de la "ética ambiental" y la "ética animal" a partir de las contribuciones de diferentes pensadores "del Norte" en relación con los recientes ensayos en desarrollo en "el Sur" respecto a la consagración política y jurídica del "Buen Vivir" y de los "derechos de la naturaleza" en Ecuador y Bolivia. Por último, se identifica en la consagración de "derechos a lo no humano" una expresión articuladora entre las diferentes propuestas de desmercantilización que constituye, a su vez, una novedosa manera de abordar la "cuestión animal". 
RESUM: Aquest article té com a objectiu caracteritzar les diferents respostes que s'han elaborat davant del comerç creixent d'animals no humans i les seves traduccions respectives en el camp jurídic, entre les quals s'han identificat, a efectes analítics, dos grans programes: d'una banda, la "protecció mitjançant la regulació del comerç" i, de l'altre, la "protecció mitjançant la desmercantilització del que és viu". Des d'aquesta perspectiva s'analitza, en primer lloc, la Convenció sobre el comerç internacional d'espècies amenaçades de fauna i flora silvestres (CITES), la qual cosa permet presentar els elements medul-lars del primer programa. Després, s'investiga al voltant de les aportacions de l" "ètica ambiental" i de l'"ètica animal" a partir de les contribucions de diferents pensadors del "Nord" en relació amb els assajos recents que es desenvolupen en el "Sud" en relació a la consagració política i jurídica del "Bon Viure" i dels "drets de la naturalesa" a l'Equador i a Bolívia. En darrer lloc, s’identifica en la consagració de "drets a allò no humà" una expressió articuladora entre les diferents propostes de desmercantilització que constitueix, de la mateixa manera, una camí nou a l'hora d'abordar la "qüestió animal".

ABSTRACT: The aim of this article is to characterize the various responses that have been formulated against the growing trade in non-human animals and their respective translations to the legal field, among which two programs have been identified for analytical purposes: on the one hand, "protection by regulating trade", and on the other hand, "protection by the non-commodification of the living." From this perspective, the Convention on International Trade in Endangered Species of Wild Fauna and Flora (CITES) is analysed to present the core elements of the first program. Then, an analysis is made of "environmental ethics" and "animal ethics", and in particular the contributions of various thinkers from "the North" and how they link up with recent developments in "the South": the political and legal establishment of the Buen Vivir (Good Way of Living) and the "rights of nature" in Ecuador and Bolivia. Finally, the acceptance of "non-human rights" is considered to be the concept that brings together different non-commodification proposals and, in turn, represents a new way of addressing the "animal issue".

PALABRAS CLAVE: Protección de la fauna - Derechos de los animales Derechos de la naturaleza - Regulación del comercio - Desmercantilización. 
PARAULES CLAU: Protecció de la fauna — Drets dels animals — Drets de la naturalesa — Regulació del comerç — Desmercantilització.

KEY WORDS: Wildlife protection - Animal rights - Rights of nature - Regulation of trade - Non-commodification.

SUMARIO: I. Introducción. II. La Convención sobre el Comercio Internacional de Especies Amenazadas de Fauna y Flora Silvestres (CITES). 1. Antecedentes, misión y estructura de la CITES. 2. Discusiones de la época y perspectivas dominantes en materia de conservación. III. Entre la regulación del comercio y la desmercantilización de lo vivo. 1. Proteger mediante la regulación del comercio. 2. Proteger mediante la desmercantilización de lo vivo. 3. El reconocimiento de derechos a lo no humano como expresión articuladora de las diferentes propuestas de desmercantilización. IV. Algunas reflexiones finales. V. Referencias bibliográficas. 1. Libros. 2. Capítulos de libros. 3. Artículos de revista. 4. Documentos.

\section{INTRODUCCIÓN}

En el presente artículo se analizan, desde una perspectiva sociojurídica, las tensiones y los puntos de convergencia entre los diferentes programas para el gobierno de "lo vivo" y sus respectivas traducciones al campo jurídico en relación con la "cuestión animal": la "protección mediante la regulación del comercio" y la "protección mediante la desmercantilización de lo vivo".

En el primer apartado se presenta una de las regulaciones más relevantes a nivel internacional: la Convención sobre el Comercio Internacional de Especies Amenazadas de Fauna y Flora Silvestres (CITES), que ubica al comercio como eje para dar respuesta a la extinción de especies. Se examinan sus antecedentes, misión y estructura, así como las discusiones de la época y las perspectivas dominantes en materia de conservación.

En el segundo apartado se efectúa una comparación entre el programa de regulación del comercio y el de desmercantilización de lo vivo. En relación con esta última, se relacionan los aportes provenientes "del Norte" -Europa y Estados Unidos-, identificados con las nociones de "ética ambiental" y "ética animal", con los ensayos en desarrollo en "el Sur" que recogen normativamente formas de vida ancestrales de pueblos indígenas latinoamericanos en diálogo con movimientos sociales de diferente

\footnotetext{
1 La "cuestión animal" engloba una serie de cuestiones que tienden a repensar, desde diferentes perspectivas y disciplinas, la relación entre animales humanos y no humanos.
} 
tipo y que desembocaron en el reconocimiento de la Pachamama ${ }^{2}$ o Madre Tierra como sujeto de derecho en Ecuador y en Bolivia, y que, a su vez, han comenzado a proyectarse tanto hacia otros países como hacia la esfera internacional ${ }^{3}$.

El abordaje de la temática pretende contribuir al debate y a la elaboración de herramientas teóricas y jurídicas sobre la problemática de la extinción de especies, dado que, si bien esta ha adquirido visibilidad en el ámbito académico, con especial relevancia en la intersección entre derecho y ética, los avances que se observan no son suficientes ${ }^{4}$. En este contexto, se propone tornar visibles las posiciones y los discursos éticos que permean las normativas vigentes $y$, en paralelo, contribuir a generar insumos para repensar las regulaciones y los diseños institucionales.

\footnotetext{
${ }^{2}$ El término Pachamama procede de la lengua quechua y es un término equivalente a Madre Tierra. Se compone de dos vocablos: Pacha, que se traduce como 'universo', 'mundo', 'tiempo', 'lugar'..., y Mama, que significa 'madre'.

${ }^{3}$ En 2010, frente al fracaso de las negociaciones sobre cambio climático en Copenhague, se impulsó la Declaración Universal de los Derechos de la Madre Tierra, aprobada por 35.000 personas en Cochabamba, en la cual se considera que "todos y todas somos parte de la Madre Tierra, una comunidad indivisible vital de seres interdependientes e interrelacionados con un destino común" y se afirma "que para garantizar los derechos humanos es necesario reconocer y defender los derechos de la Madre Tierra y todos los seres, y que hay culturas, prácticas y leyes que lo hacen”. Véase en: Conferencia Mundial de los Pueblos sobre el Cambio Climático y los Derechos de la Madre Tierra. (2010, 24 de abril). Declaración Universal de los Derechos de la Madre Tierra. Recuperado el 12 de noviembre de 2015, de http://rio20.net/propuestas/declaracion-universal-de-los-derechos-de-la-madre-tierra/. La Declaración de Cochabamba repercutió en las resoluciones de la ONU sobre "armonía con la naturaleza"; por ejemplo, en la Resolución 65/164, aprobada por la Asamblea General el 20 de diciembre de 2010, se "hace notar" la primera Conferencia Mundial de los Pueblos sobre el Cambio Climático y los Derechos de la Madre Tierra y se reconoce "que muchas civilizaciones antiguas y culturas indígenas tienen una historia rica de comprensión de la conexión simbiótica entre los seres humanos y la naturaleza que promueve una relación mutuamente beneficiosa". Véase en: Naciones Unidas. (2010, 20 de diciembre). Resolución 65/164. Armonía con la naturaleza. Recuperado el 12 de noviembre de 2015, de http://www.un.org/en/ga/search/view_doc.asp?symbol=A/RES/65/164\&Lang=S. Por su parte, el documento final de la Conferencia Río+20, titulado "El futuro que queremos", reconoce, en el párrafo 39, al planeta Tierra como "nuestro hogar" y a la expresión "Madre Tierra" como común para varios países y regiones, observando, a su vez, que algunos países han reconocido los derechos de la naturaleza "en el contexto de la promoción del desarrollo sostenible". Véase en: Naciones Unidas. (2012, 22 de junio). Conferencia de las Naciones Unidas sobre el Desarrollo Sostenible Río+20. El futuro que queremos. Recuperado el 12 de noviembre de 2015, de https://rio20.un.org/sites/rio20.un.org/files/a-conf.216-11_spanish.pdf.pdf. Recientemente un grupo de abogados/as, organizaciones no gubernamentales ambientalistas y académicos se reunieron con el fin de iniciar el mecanismo de Iniciativa Ciudadana Europea (ECI) para presentar una propuesta a la Comisión Europea cuyo objetivo es lograr el reconocimiento de los derechos de la naturaleza por medio de una directiva.

${ }^{4}$ En el Informe Planeta Vivo, edición 2014, se afirma que el Índice Planeta Vivo (IPV), que analiza más de 10.000 poblaciones representativas de mamíferos, aves, reptiles, anfibios y peces, ha disminuido un 52 por ciento desde 1970. Fuente: World Wildlife Fund et ál. Living Planet. Report 2014. Species and spaces, people and places. Recuperado el 18 de diciembre de 2015, de http://www.worldwildlife.org/pages/living-planet-report-2014.
} 


\section{LA CONVENCIÓN SOBRE EL COMERCIO INTERNACIONAL DE ESPECIES AMENAZADAS DE FAUNA Y FLORA SILVESTRES (CITES)}

El comercio de fauna silvestre aumenta día a día, lo que pone en peligro la supervivencia de una gran cantidad de especies y produce, a su vez, efectos devastadores en los ecosistemas y las comunidades donde habitan ${ }^{5}$. Intentando brindar una respuesta a esta problemática, el 3 de marzo de 1975, tras la firma de diez Estados, entró en vigor la Convención sobre el Comercio Internacional de Especies Amenazadas de Fauna y Flora Silvestres (CITES).

\section{Antecedentes, misión y estructura de la CITES}

Sus antecedentes se remontan a la VII Asamblea General de la Unión Internacional para la Conservación de la Naturaleza y los Recursos Naturales — denominada actualmente Unión Internacional para la Conservación de la Naturaleza (UICN) ${ }^{6}$-, celebrada en 1960 en Varsovia, Polonia. En esta, los delegados expresaron su preocupación por el daño que causaba el comercio internacional de especies silvestres ${ }^{7}$ e instaron a que los gobiernos limitaran la importación de fauna conforme a la reglamentación de exportación de los países de origen ${ }^{8}$. Sin embargo, esta medida no resultó efectiva, dado que las reglamentaciones distaban de ser uniformes y los gobiernos no tenían conocimiento de las de otros países o no disponían de herramientas jurídicas para apoyarlas ${ }^{9}$.

\footnotetext{
${ }^{5}$ De las 79.837 especies evaluadas en la Lista Roja de la UICN -el más completo inventario del estado de conservación de especies de animales y plantas a nivel mundial-, 23.250 están en peligro de extinción, siendo el comercio ilegal, junto con el deterioro y la pérdida del hábitat, una de las principales amenazas. Fuente: International Union for Conservation of Nature. The IUCN Red List of Threatened Species. Version 2015-4. Recuperado el 17 de noviembre de 2016, de http://www.iucnredlist.org.

${ }^{6}$ La UICN es una organización internacional ambiental fundada en 1948 y destinada a la conservación de la naturaleza y los recursos naturales. Establece estándares de políticas ambientales y reúne, entre sus miembros, a Estados, agencias gubernamentales y sectores de la sociedad civil con el objetivo de promover el desarrollo sostenible y la conservación de la biodiversidad. Más información en: http://www.iucn.org/es/que/.

${ }^{7}$ KAKABADSE, Y., "Carta Magna para la vida silvestre", Conservación Mundial. El comercio de especies. La CITES en el nuevo milenio, vol. 33, núm. 3, 2002, p. 3.

${ }^{8}$ WIJNSTEKERS, W., The Evolution of CITES, $9^{\mathrm{a}}$ ed., International Council for Game and Wildlife Conservation, 2011.

${ }^{9}$ Convención sobre el Comercio Internacional de Especies Amenazadas de Fauna y Flora Silvestres. (2003, 3 de marzo). CITES en el Mundo. Boletín Oficial de las Partes. Recuperado el 28 de noviembre de 2015, de https://www.cites.org/sites/default/files/esp/news/world/30special.pdf.
} 
Tres años después, en 1963, la Asamblea General de la UICN, celebrada en Nairobi, Kenia, emitió una resolución por la que se solicitaba la creación de un convenio que reglamentara la exportación, la importación y el tránsito de especies amenazadas ${ }^{10}$. El primer proyecto surge en 1964, y durante una década el equipo legal de la UICN, dirigido por Wolfgang Burhenne y Françoise Burhenne, preparó una sucesión de borradores que circularon entre gobiernos y organizaciones no gubernamentales, tres de los cuales fueron remitidos a los miembros de las Naciones Unidas: el primero en 1967, el segundo en 1969 y el tercero en 1971. Por su parte, en 1969, en el marco de la X Asamblea General de la UICN (Nueva Delhi, India), se presentó un proyecto de lista de especies cuyo comercio debía ser regulado por la convención, proyecto que fue revisado y modificado por 39 gobiernos y 18 ONG entre 1969 y 1971.

No obstante, sería la Conferencia de las Naciones Unidas sobre el Medio Humano celebrada en Estocolmo, Suecia, entre el 5 y 16 de junio de 1972, la que daría el impulso final para que se debatiera el proyecto definitivo mediante la Recomendación 99.3, que instó a que "se convoque lo antes posible, bajo los auspicios gubernamentales o intergubernamentales adecuados, una conferencia de plenipotenciarios encargados de redactar y aprobar una convención sobre la exportación, la importación y el tránsito de ciertas especies de animales salvajes y plantas silvestres"11.

La Conferencia de Plenipotenciarios aprobó realizar la Convención Internacional sobre el Comercio de Ciertas Especies de Fauna y Flora Silvestres —llamada también Conferencia Mundial sobre la Vida Silvestre-, que fue organizada por los Estados Unidos y se celebró en el Pentágono, Washington, entre el 12 de febrero y el 2 de marzo de 1973. En ella participaron representantes de 80 países, así como representantes de 8 países y 6 organizaciones internacionales en calidad de observadores, y dio por resultado, el 3 de marzo de ese mismo año, luego de tres semanas de deliberaciones y bajo la firma de 21 de los 80 países que participaron en la Conferencia, la Carta Magna de la Vida Silvestre, como fue llamada en ese momento la CITES, que entró en vigor el 1 de julio de 1975 tras la ratificación de diez Estados $^{12}$.

\footnotetext{
${ }^{10}$ WIJNSTEKERS, The Evolution... cit.

${ }^{11}$ Naciones Unidas. (1972, 16 de junio). Declaración de la Conferencia de las Naciones Unidas sobre el Medio Humano. Recuperado el 18 de noviembre de 2015, de http://www.ambiente.gov.ar/infotecaea/descargas/estocolmo01.pdf.

${ }^{12}$ Canadá, Chile, Chipre, Ecuador, Estados Unidos, Nigeria, Suecia, Suiza, Túnez y Uruguay.
} 
Se estableció la Conferencia de las Partes como órgano de adopción de decisiones, encargada, entre otras atribuciones, de formular recomendaciones y enmendar los apéndices, y Suiza se ofreció a actuar como Gobierno depositario de la Convención. Se constituyó una secretaría, administrada por el Programa de las Naciones Unidas para el Medio Ambiente (PNUMA), encargada de organizar las reuniones, realizar estudios y preparar informes, entre otras atribuciones. Conforme a la Visión Estratégica de la CITES: 2008-2020, su “misión” consiste en:

Conservar la diversidad biológica y contribuir a su utilización sostenible, velando por que ninguna especie de fauna o flora silvestres se someta o se siga sometiendo a una explotación insostenible debido al comercio internacional, contribuyendo así a una reducción considerable del índice de pérdida de biodiversidad y aportando una contribución significativa para lograr las Metas de Aichi ${ }^{13}$ para la Diversidad Biológica relevantes ${ }^{14}$.

La CITES se basó en la idea de que el comercio de vida silvestre sería controlado por listas de especies amenazadas preparadas y actualizadas continuamente por expertos ${ }^{15}$, para lo cual tomó como antecedente la Lista Roja de Especies Amenazadas, publicada por la UICN desde 1963. En consecuencia, las especies de fauna y flora fueron distribuidas en tres apéndices con diferentes niveles de protección ${ }^{16}$. El texto de la

\footnotetext{
${ }^{13}$ Las Metas de Aichi surgen del Plan Estratégico para la Diversidad Biológica 2011-2020 adoptado por la X Reunión de la Conferencia de las Partes del Convenio de Naciones Unidas sobre la Diversidad Biológica (COP 10), el cual establece cinco objetivos estratégicos y veinte metas para "detener la pérdida de diversidad biológica a fin de asegurar que, para 2020, los ecosistemas sean resilientes y sigan suministrando servicios esenciales, asegurando de este modo la variedad de la vida del planeta y contribuyendo al bienestar humano y a la erradicación de la pobreza". Véase en: Convention on Biological Diversity. (2010, 29 de octubre). Tenth meeting of the Conference of the Parties. Aichi Biodiversity Targets. Recuperado el 18 de enero de 2016, de https://www.cbd.int/sp/targets/.

${ }^{14}$ Convención sobre el Comercio Internacional de Especies Amenazadas de Fauna y Flora Silvestres. (2013, 14 de marzo). XVI Reunión de la Conferencia de Partes. Resolución Conf. 16.3. Visión Estratégica de la CITES: 2008-2020. Recuperado el 8 de agosto de 2015, de http://www.cites.org/esp/res/16/16-03.

${ }^{15}$ Si bien escapa a los objetivos del presente artículo, corresponde preguntarse sobre quiénes "definen” el conocimiento en este sistema, es decir, qué saberes poseen legitimidad para preparar y actualizar las listas de especies amenazadas. Las elaboraciones académicas de quienes se han dedicado a estudiar los espacios de producción de conocimiento científico se encuentran agrupadas bajo la denominación Science and Technology Studies, en su versión inglesa, que se puede traducir como 'estudios sociales de la ciencia y la tecnología'. Una introducción a este campo disciplinario se encuentra en: PESTRE, D., Introduction aux science studies, La Découverte, París, 2006.

${ }^{16}$ El apéndice I incluye todas las especies que se encuentran amenazadas de extinción, cuyo comercio internacional está prohibido, salvo algunas excepciones que solo se autorizarán en circunstancias específicas; el apéndice II incluye las especies que no se encuentran actualmente amenazadas de extinción, pero que podrían llegar a estarlo sin una estricta reglamentación de su comercio; por último, el apéndice III incluye las especies sometidas a reglamentación dentro de la jurisdicción de una parte y para las cuales el comercio no se puede controlar sin la cooperación de otras partes.
} 
convención, integrado por un preámbulo y 25 artículos, conjuga los conceptos de regulación del comercio y de conservación propuestos en los diferentes acuerdos precedentes.

\section{Discusiones de la época y perspectivas dominantes en materia de conservación}

La CITES es "hija" de la Conferencia de las Naciones Unidas sobre el Medio Humano (1972), de la cual surgió una declaración de 26 principios y un plan de acción con 10 recomendaciones que, bajo la idea de "progreso", establecen una estrecha relación entre la protección del ambiente y el desarrollo económico:

El hombre debe hacer constante recapitulación de su experiencia y continuar descubriendo, inventando, creando y progresando [...], [ya que] la capacidad del hombre de transformar lo que lo rodea, utilizada con discernimiento, puede llevar a todos los pueblos los beneficios del desarrollo y ofrecerles la oportunidad de ennoblecer su existencia ${ }^{17}$.

Esta idea de progreso se encuentra ligada, a su vez, a la dicotomía entre "países desarrollados" y "países en desarrollo"; en estos últimos, la mayoría de los problemas ambientales estarían motivados por el subdesarrollo. En 1987, el Informe Brundtland, al establecer una estrecha relación entre "pobreza" y "crisis ecológica”, encauzó el esquema del desarrollo sostenible mediante una serie de estrategias de transferencia de conocimientos y tecnologías desde los países "centrales" hacia los países "periféricos" 18 .

Bajo el marco establecido por la declaración de 1972 comienzan a surgir una serie de convenciones "post-Estocolmo" o "de primera generación". Estas regulaciones comparten esquemas similares como la incorporación de listas y un objetivo primordial: la conservación. En este sentido, la Convención Relativa a los Humedales de Importancia Internacional especialmente como Hábitat de Aves Acuáticas (1971) establece que cada parte contratante, al adherirse a esta, se compromete a designar por lo menos un humedal para incluirlo en la Lista de Humedales de Importancia

\footnotetext{
${ }^{17}$ Naciones Unidas. (1972, 16 de junio). Declaración... cit.

18 HAIDAR, V. y BERROS, V., "Entre el 'sumak kawsay' y la 'vida en armonía con la naturaleza': disputas en la circulación y traducción de perspectivas respecto de la regulación de la cuestión ecológica en el espacio global", Revista Theomai Estudios Críticos sobre Sociedad y Desarrollo, año 15, núm. 32, Buenos Aires, 2015, pp. 128-155.
} 
Internacional. Por su parte, la Convención sobre la Protección del Patrimonio Mundial (1972) crea el Comité del Patrimonio Mundial, al cual le encarga, entre otras cuestiones, llevar al día y publicar la Lista del Patrimonio Mundial, una lista de los bienes del patrimonio cultural y del patrimonio natural que poseen un valor universal excepcional.

En las convenciones "post-Río", o de "segunda generación”, comienzan a visibilizarse y entrelazarse, sobre la base del esquema del desarrollo sostenible, otros temas además de la necesidad de conservar determinadas especies o ecosistemas (la pobreza, el desarrollo, la equidad, la paz, etc.), bajo una serie de disposiciones relativas a cuestiones de financiamiento: quién y cuánto paga.

La estrategia de regular la comercialización parece visualizarse como eje del sistema protectorio respecto a la "cuestión animal". Su análisis permite construir una serie de preguntas que el presente artículo intenta dilucidar: ¿cuál es la perspectiva ética subyacente a la protección mediante la regulación del comercio?, ¿en qué lugar se sitúa al animal no humano?, ¿existen otras perspectivas desde las cuales abordar esta problemática?

\section{ENTRE LA REGULACIÓN DEL COMERCIO Y LA DESMERCANTILIZACIÓN DE LO VIVO}

Las tensiones éticas, políticas y sociales que derivan del creciente comercio de animales no humanos y sus respectivos correlatos en el ámbito jurídico dan lugar a una serie de interrogantes en el campo de las ciencias sociales que ponen en cuestión tanto las dicotomías del "pensamiento moderno" — o de la "ciencia" - como del derecho: sujetoobjeto, naturaleza-sociedad, cosa-persona, humano-animal ${ }^{19}$. Bajo ese prisma, se han delimitado en este trabajo dos grandes programas que pueden identificarse en relación con el gobierno de "lo vivo" y que se traducen, a su vez, en dos grandes respuestas jurídicas a la cuestión animal: la "protección mediante la regulación del comercio" y la "protección mediante la desmercantilización de lo vivo".

\footnotetext{
19 Sobre las dicotomías del pensamiento moderno, véase: LATOUR, B., Nous n'avons jamais été modernes. Essai d'anthropologie symétrique, La Decouverte, París, 1997.
} 


\section{Proteger mediante la regulación del comercio}

El concepto de mercantilización se encuentra ligado a la noción de economía de mercado. Lo que caracteriza a esta última es que, a diferencia de lo ocurrido en otros momentos históricos donde ha habido economías "con" mercados, en el contexto actual dicha institución resulta absolutamente hegemónica y condiciona el funcionamiento social en su totalidad ${ }^{20}$. El proceso de mercantilización ha ido afectando a un sinnúmero de ámbitos tales como el trabajo, la salud y la educación, etc., y, entre la diversidad de cuestiones que han sido modificadas, invisibilizadas, redefinidas y colonizadas por este proceso, se encuentra la naturaleza.

La naturaleza ha adquirido diversos significados que han sido el resultado de procesos históricos, sociopolíticos, culturales y económicos. Es así que la humanidad ha visto en ella una "frontera salvaje" amenazadora e incontrolable; una "canasta de recursos" de los que apropiarse a fin de utilizarlos para satisfacer necesidades" ${ }^{21}$; un "sistema" con mecanismos propios, con ciclos que deben ser estudiados y respetados; o un "capital" que debe incluirse en los procesos económicos y al cual debe atribuirse un valor en dinero $^{22}$.

Esta noción de naturaleza como capital es la conceptualización propia del proceso de mercantilización, cuya respuesta consiste en asignar a los elementos de la naturaleza un valor económico que refleje lo que las personas están dispuestas a pagar por ellos, sea para apropiárselos o para protegerlos. Esta perspectiva se encuentra íntimamente relacionada con la idea de "naturaleza fragmentada", donde los diferentes "elementos" que la componen se encuentran "atomizados" y agrupados bajo la noción de "recursos naturales", la cual involucra un conjunto de entes desvinculados unos de otros, reducidos al concepto jurídico de "cosa" — propio del derecho real—y sujetos a las normas que regulan el derecho de propiedad.

\footnotetext{
${ }^{20}$ UNCETA, K., "Poscrecimiento, desmercantilización y 'buen vivir'”, Nueva Sociedad, núm. 252, 2014, pp. 136-152. También se ha hecho referencia a una "omnimercantilización del mundo" en: LATOUCHE, S., Limite, Adriana Hidalgo editora, Buenos Aires, 2014.

${ }^{21}$ Se trata de una suerte de "derecho a destruir" presente en la mayoría de los ordenamientos jurídicos modernos. Véase en: RÈMOND-GOUILLOUD, M., El derecho a destruir. Ensayo sobre el derecho del medio ambiente, Losada, Buenos Aires, 1994.

22 GUDYNAS, E., "Concepciones de la naturaleza y desarrollo en América Latina”, Persona y Sociedad, vol. 13, núm. 1, 1999, pp. 101-125.
} 
La conceptualización de la naturaleza resulta ineludible a la hora de abordar las diferentes respuestas que pueden brindarse a problemáticas relativas a su deterioro, entre las cuales se encuentra la extinción de especies. La protección mediante la regulación del comercio parte de la noción de la naturaleza como capital y de la idea de que los animales no humanos son "cosas" 23 , pero toma consciencia de la importancia de estos últimos para la satisfacción de las necesidades humanas, por lo que busca, mediante un conjunto de normas tendientes a regular el intercambio, establecer una serie de límites al comercio con el fin de proteger determinadas especies.

${ }^{23}$ La codificación moderna - tanto en Europa como en Latinoamérica - ha regulado, en términos generales, los animales no humanos como "cosa apropiable" (derechos reales) o "cosa riesgosa" (responsabilidad civil). Verbigracia, el Código Civil español de 1889 regula los animales no humanos entre las normas de la propiedad (arts. 355 y 357), de la posesión (art. 465), del usufructo (art. 499), de los modos de adquirir la propiedad (arts. 610 y 612), de las obligaciones del vendedor en relación con la cosa (entrega y saneamiento, arts. 1491/99) y, por último, de las obligaciones que nacen de la culpa o negligencia (responsabilidad del poseedor de un animal, art. 1905). Por su parte, el Código Civil argentino de Vélez Sarsfield —aprobado en 1869 y vigente hasta julio de 2015 — también encuadró los animales no humanos bajo el concepto de "cosa" en la perspectiva del derecho de propiedad: todo "objeto material susceptible de tener un valor" (art. 2311); a la fauna silvestre, más específicamente, la consideró una "cosa sin dueño" (arts. 2525 y 2527). El nuevo Código Civil y Comercial de Argentina, aprobado en el 2014, no ha realizado mayores modificaciones en relación con esto: en él se reproducen los postulados del Código velezano en el título V del libro III (véanse artículos 2527, 2540/44, 2592 y 2605). Sin embargo, en paralelo, jurisprudencia reciente afirma el carácter de sujeto de derecho de los animales; un fallo novedoso en la materia fue emitido el 18 de diciembre de 2014 por la Sala II de la Cámara Federal de Casación Penal al resolver que corresponde tramitar un habeas corpus iniciado a favor de la orangutana Sandra, estableciendo, entre sus considerandos, que los animales son "sujetos no humanos" y, por lo tanto, titulares de derechos. Un análisis en contexto de la sentencia puede encontrarse en: BERROS, V., "Breve contextualización de la reciente sentencia sobre el habeas corpus en favor de la orangutana Sandra: entre ética animal y derecho", Revista de Derecho Ambiental, núm. 41, AbeledoPerrot, Buenos Aires, 2015. A su vez, el Código Civil chileno, que influyó en el proceso de codificación de Ecuador, Colombia, Nicaragua, Honduras, El Salvador y Panamá, regula los animales en relación con la clasificación de las cosas (art. 567), la ocupación como modo de adquirir el dominio de las cosas que no pertenecen a nadie (art. 607) y los delitos y cuasidelitos en casos de responsabilidad por el daño causado por animales, entre otros postulados que abordan la cuestión animal desde el derecho de propiedad. Un caso particular se presenta en el derecho francés, donde, mediante una enmienda adoptada por la Asamblea Nacional, los animales dejaron de ser considerados "bienes muebles" para ser considerados "seres vivos dotados de sensibilidad" (art. 515-14 del Código Civil francés). Además de Francia, también Austria, Alemania y Suiza han modificado su legislación en relación con los animales. Austria excluyó los animales del concepto de "cosa" mediante una ley en 1988 y en el año 2004 incorporó en su Constitución (Bundes-Verfassungsgesetz) una disposición según la cual el Estado protege la vida y el bienestar de los animales; en sentido similar avanzó la legislación alemana al modificar el Código Civil (Bürgerliches Gesetzbuch) mediante la Ley para la Mejora de la Situación Jurídica del Animal en el Derecho Civil (Gesetz zur Verbesserung der Rechtsstellung des Tieres im bürgerlichen Recht), de 1990, por la cual se estableció que los animales no son cosas y que están protegidos por las leyes especiales, y mediante una disposición introducida en la Ley Fundamental (Grundgesetz für die Bundesrepublik Deutschland), en el año 2002, en relación con la protección de los animales por medio del ejercicio del poder legislativo, ejecutivo y judicial; Suiza presenta una nota distintiva al extender la protección a todas las criaturas vivientes como obligación constitucional desde el año 2000, obligación incorporada al Código Civil (Schweizerische Zivilgesetzbuch) en el año 2004; el Código Civil de Cataluña, en sintonía con las reformas mencionadas, establece en su artículo 511-1, referido a los bienes, que los animales "no se consideran cosas" y que "están bajo la protección especial de las leyes", agregando que se les aplican las reglas de los bienes solo "en lo que permite su naturaleza". Véase en: GIMÉNEZ-CANDELA, T., "Estatuto jurídico de los animales: aspectos comparados", Baltasar, B. (coord.), El derecho de los animales, Marcial Pons, Madrid, 2015, pp. 149-184. 
Como ejemplo ilustrativo, la doctrina de la época en que se ratificó la CITES en Argentina consideró que su objetivo es controlar y reglamentar a nivel mundial el comercio de animales y plantas como política de conservación y utilización racional de esos "recursos" 24 . Por su parte, en el preámbulo de la Convención se reconoce que la protección de la flora y fauna silvestres debe ser en beneficio de "esta generación y las venideras", y, a su vez, se considera el "creciente valor de la fauna y flora silvestres desde los puntos de vista estético, científico, cultural, recreativo y económico".

Ambos postulados dejan traslucir el carácter antropocéntrico que subyace a su articulado, el cual se corresponde, a su vez, con un esquema de protección mediante la regulación del comercio ${ }^{25}$ que encuentra una de sus mayores expresiones en el artículo VII inc. 4, donde se establece que "[1] os especímenes de una especie animal incluida en el Apéndice I y criados en cautividad para fines comerciales [...], serán considerados especímenes de las especies incluidas en el Apéndice II", aminorándose de esta manera la protección de los animales por razones de mero interés humano.

Las normativas nacionales sobre protección de fauna — tanto de países europeos como latinoamericanos - mantienen, por lo general, el carácter antropocéntrico del derecho internacional y regulan los animales no humanos como recursos naturales, es decir, consideran el animal no humano como un elemento del ecosistema que hay que proteger en beneficio de los seres humanos ${ }^{26}$. Entre las normativas representativas de este enfoque pueden mencionarse, con fines meramente informativos, una serie de leyes y

\footnotetext{
${ }^{24}$ GONZÁLEZ RUIZ, E., "Ejecución de la Convención sobre el Comercio Internacional de Especies Amenazadas de Fauna y Flora Silvestres (CITES) en la República Argentina", Ambiente y Recursos Naturales. Revista de Derecho, Política y Administración, vol. 2, núm. 1, La Ley, Buenos Aires, 1985, pp. 19-25; y MENGUI, O., "CITES: Un acuerdo de importancia capital para la conservación de la fauna y flora mundiales", Ambiente y Recursos Naturales. Revista de Derecho, Política y Administración, vol. 1, núm. 2, La Ley, Buenos Aires, 1985, pp. 11-14.

${ }^{25}$ Sin embargo, en otros instrumentos internacionales podemos encontrar "huellas" de éticas alternativas al antropocentrismo. En este sentido, el Convenio sobre la Diversidad Biológica reconoce el "valor intrínseco" y la "importancia de la diversidad biológica para la evolución y para el mantenimiento de los sistemas necesarios para la vida de la biosfera". No obstante, el principio antropocéntrico de equidad intergeneracional - conservar para las generaciones actuales y futuras- también se encuentra presente, junto con otros postulados que insisten en la "utilización sostenible" y en la importancia de la diversidad biológica "para satisfacer las necesidades alimentarias, de salud y de otra naturaleza de la población mundial".

${ }^{26}$ Distinto es el caso de las normativas que promueven el bienestar animal, entre las cuales pueden nombrarse: en Argentina, la Ley 14.346/54, de 27 de septiembre, de malos tratos y actos de crueldad a los animales; en Colombia, la Ley 84/1989, de 27 de diciembre, de Estatuto Nacional de Protección de los Animales; y en Chile, la Ley 20.380/2009, de 3 de octubre, de protección de animales. Estas normas se caracterizan, en general, por combatir el maltrato animal y promover "buenas prácticas", sin reconocer necesariamente a los animales no humanos como sujetos de derecho ni discutir su utilización en experimentación, producción, consumo, etc.
} 
decretos sancionados entre mediados y finales del siglo XX en Argentina y la Ley española 42/2007, de 13 de diciembre, del Patrimonio Natural y de la Biodiversidad.

En Argentina, en la década de 1980, además de aprobarse la CITES mediante la Ley $\mathrm{N}^{\circ}$ 22.344/1980, de 1 de diciembre, se actualiza la Ley $\mathrm{N}^{\circ} 13.908 / 1950$, de 19 de julio, de conservación de fauna, con la sanción de la Ley $\mathrm{N}^{\mathrm{o}} 22.421 / 1981$, de 5 de marzo, y en 1986 se suspende tanto el comercio internacional como interprovincial de ejemplares vivos de todas las especies de la fauna autóctona y criadas en cautiverio (con excepción de todas las consideradas dañinas o perjudiciales) mediante la Resolución $N^{\circ}$ 62/1986, de 31 de enero, de la Secretaría de Agricultura, Ganadería y Pesca ${ }^{27}$. En el año 1997 se deroga el Decreto $\mathrm{N}^{\circ}$ 691/81, de 27 de marzo, reglamentario de la Ley $\mathrm{N}^{\circ} 22.344 / 1980$, y se reemplaza por el Decreto 522/97, de 5 de junio; la Ley $\mathrm{N}^{0} 22.421 / 1981$ es reglamentada ese mismo año mediante el Decreto 666/97, de 18 de julio.

La Ley $\mathrm{N}^{\circ} 22.421 / 1980$ establece que, conforme a las disposiciones legales $\mathrm{y}$ reglamentarias nacionales y provinciales, "el propietario del campo podrá aprovechar la fauna silvestre que lo habita transitoria o permanentemente, debiendo protegerla y limitar racionalmente su utilización para asegurar la conservación de la misma”. En el capítulo III regula el comercio interprovincial e internacional, donde encontramos una serie de disposiciones, en sintonía con las respuestas brindadas por la CITES al comercio de animales no humanos, que hemos denominado de "protección mediante la regulación del comercio”. En relación con esto último, el Decreto 522/97 establece que la CITES “es un instrumento adecuado para fomentar la cooperación internacional y así lograr la protección de ciertas especies contra el comercio excesivo, con el fin de asegurar su supervivencia”. Por último, el Decreto 666/97 regula en el capítulo II el "aprovechamiento racional de la fauna silvestre", y establece que la autoridad de aplicación, "sobre la base de los estudios y evaluaciones realizadas respecto de aquellas especies de la fauna silvestre cuya utilización fuera posible y conveniente, elaborará planes nacionales de manejo a efectos de lograr un aprovechamiento racional y sostenible de las mismas".

\footnotetext{
${ }^{27}$ Desde 1976, en concordancia con la instauración de los regímenes neoliberales en Latinoamérica, se incrementó el comercio legal de fauna en el continente y Argentina se convirtió en el mayor exportador de América del Sur. Las exportaciones aumentan hasta 1980 y luego disminuyen significativamente, por dos causas: las restricciones al comercio legal como consecuencia de la adhesión de Argentina a la CITES y una variación en los criterios cambiarios oficiales que hizo más conveniente afrontar los riesgos del tráfico ilegal que someterse a las regulaciones nacionales sobre el monto de exportaciones. Véase en: BRAILOVSKY, A. y FOGUELMAN, D., Memoria verde. Historia ecológica de la Argentina, Debolsillo, Buenos Aires, 2013.
} 
En España, por su parte, la Ley 42/2007, de 13 de diciembre, del Patrimonio Natural y de la Biodiversidad, establece, entre sus principios (art. 2), el "mantenimiento de los procesos ecológicos esenciales y de los sistemas vitales básicos, respaldando los servicios de los ecosistemas para el bienestar humano", y define los "recursos biológicos" como "los recursos genéticos, los organismos o partes de ellos, las poblaciones, o cualquier otro tipo del componente biótico de los ecosistemas de valor o utilidad real o potencial para la humanidad" (art. 3). A su vez, en el preámbulo se afirma que la desaparición de especies de fauna silvestres, entre otras problemáticas medioambientales, se ha convertido en motivo de "seria preocupación para los ciudadanos, que reivindican su derecho a un medio ambiente de calidad que asegure su salud y su bienestar". En el artículo 73 se regula el comercio internacional de especies silvestres, el cual "se llevará a cabo de manera sostenible y de acuerdo con la legislación internacional", mencionando explícitamente la CITES junto con otras normativas de carácter internacional.

Estos ejemplos — cuya perspectiva puede observarse en otros ordenamientos jurídicos en vigor tanto en América Latina como en Europa - son ilustrativos del carácter antropocéntrico que subyace a las normas para la protección de la fauna en países de ambos continentes, las cuales presentan como objetivo, en líneas generales, proteger la fauna en resguardo de las generaciones presentes y futuras, reconociendo en los animales no humanos valores económicos, culturales, científicos y educativos, entre otros valores afines a intereses humanos, $\mathrm{y}$, en relación con el comercio, reproducen el esquema de protección mediante la regulación propuesto por la CITES.

\section{Proteger mediante la desmercantilización de lo vivo}

Los procesos de desmercantilización parten de una crítica a la modernidad que rechaza, primordialmente, el modelo de desarrollo hegemónico, la visión lineal de la historia, el carácter totalizador de la ciencia moderna, la concepción atomizada y desarticulada de la naturaleza, la visión antropocéntrica y utilitarista del desarrollo y la lógica del sistema capitalista de transformarlo todo en mercancía ${ }^{28}$, y se orientan, a su vez, a reducir la

\footnotetext{
${ }^{28}$ HOUTART, F., "El concepto de Sumak Kawsai y su correspondencia con el bien común de la humanidad", América Latina en Movimiento, 2011, pp. 1-20.
} 
esfera del mercado, promoviendo otras formas de relación social y otras maneras de hacer frente a las necesidades humanas y no humanas ${ }^{29}$.

Entre el conjunto amplio y heterogéneo de críticas que se han efectuado a distintos aspectos del "pensamiento moderno", resulta necesario destacar, a los fines del presente artículo, los aportes realizados “desde el Norte” por la "ética ambiental”, por una parte, y la noción de "Buen Vivir", por otra, que ha adquirido relevancia en algunos países "del Sur".

La ética ambiental, vista como un incipiente cambio de paradigma en la filosofía moral, intenta fundar una "teoría del valor" que le atribuya "moralidad" —un valor independiente de su utilidad - a seres no humanos, verbigracia, animales, plantas, especies o ecosistemas. Desde una perspectiva más específicamente "animal", cabe destacar los aportes de Peter Singer ${ }^{30}$ Tom Regan $^{31}$ y Gary Francione ${ }^{32}$, entre otros ${ }^{33}$, los cuales se podrían articular con el contenido que propone, aunque de forma más general, la postura ética biocéntrica. El "biocentrismo" se caracteriza por ser una "posición moral que considera relevante a la vida por sí misma, esto es, al margen de la

\footnotetext{
${ }^{29}$ UNCETA, "Poscrecimiento..." cit.

${ }^{30}$ Peter Singer es un filósofo australiano que inicia sus estudios en el campo de la ética animal en la Universidad de Oxford, donde conoce a un grupo de vegetarianos y comienza a indagar sobre experimentación con animales no humanos y granjas industriales. En 1975 publica Liberación animal, un clásico del pensamiento animalista. Con una clara influencia de la tradición utilitarista, Singer propone extender la consideración moral en razón de la capacidad de sentir placer o dolor, e introduce, a su vez, el concepto de "especismo", que se refiere a la discriminación en razón de especie. Véase en: SINGER, P., Liberación animal, Trotta, Madrid, 1999.

${ }^{31}$ Tom Regan es un filósofo estadounidense que, a diferencia de Peter Singer, cuya postura pretende no abordar la "cuestión animal" en clave de derechos, propone la construcción de una "teoría de los derechos de los animales" basada en la idea del "valor inherente" de los animales no humanos. Tanto Tom Regan como Peter Singer son categorizados, en el interior de la ética animal, como pensadores de la "primera generación". Su teoría de los derechos de los animales se encuentra en: REGAN, T., The case for animals rights, University of California Press, California, 2004.

${ }^{32}$ Gary Francione propone un enfoque "abolicionista" que, en contraposición con la postura "reformista" de quienes promueven el "bienestar animal", considere moralmente injustificable la categorización de los animales no humanos como cosa y su sometimiento a los regímenes que regulan el derecho de propiedad. Es considerado como un pensador de la "segunda generación". Véase en: FRANCIONE, G., Animals, Property, and the Law, Temple University Press, Philadelphia, 1995.

${ }^{33}$ En España, por ejemplo, se destacan los aportes de Jorge Riechmann y Jesús Mosterín. Ambos autores han abordado la cuestión animal tanto desde un enfoque filosófico, en relación con la extensión de la consideración moral a los animales no humanos, como desde un enfoque jurídico, es decir, respecto a la posibilidad de considerar los animales no humanos titulares de derechos subjetivos. Véase en: RIECHMANN, J. y MOSTERIN, J., Animales y ciudadanos, Talasa, Madrid, 1995.
} 
subjetividad de quien la experimenta. Así, todos los seres vivos, por el hecho de serlo, estarían dotados de valor moral" ${ }^{\prime 4}$.

En paralelo a las posturas biocéntricas, surgen también desde la ética ambiental enfoques "ecocéntricos" que retoman el concepto de ecología acuñado por Ernst Haeckel para elaborar una postura que considere que el "mundo natural" posee un valor intrínseco ${ }^{35}$; dentro de este enfoque destacan los aportes de Aldo Leopold ${ }^{36}$ y Arne $\mathrm{Naess}^{37}$, que se caracterizan por concebir las especies o los ecosistemas como entidades moralmente considerables.

Estas posturas, que surgen en el interior de la ética en conjunción con una serie de movimientos socioambientales en los Estados Unidos y en Europa ${ }^{38}$, podrían aportar al campo jurídico un cúmulo de fundamentos para percibir la extinción de especies animales como algo negativo per se, es decir, al margen de la utilidad que se deriva de su instrumentalización con fines comerciales, productivos o estéticos, abriendo senderos a una suerte de "solidaridad interespecie":

La toma de conciencia de que la supervivencia de la especie humana está estrechamente relacionada con la supervivencia de las otras especies, sugiere e instaura una solidaridad necesaria con respecto al mundo viviente y a la naturaleza en general, superando cada residuo de antropocentrismo y de dualismo. Esta nueva solidaridad nos anuncia nuevas y diversas modalidades de relación entre los

\footnotetext{
${ }^{34}$ ESQUIVEL FRÍAS, L., Responsabilidad y sostenibilidad ecológica. Una ética para la vida, Facultad de Filosofía y Letras, Universidad Autónoma de Barcelona, 2006, p. 39.

35 BERROS, V., "El estatuto jurídico de la naturaleza en debate (meulen en el mundo del derecho)", Revista de Derecho Ambiental, núm. 36, Abeledo-Perrot, Buenos Aires, 2013.

${ }^{36}$ Aldo Leopold, en su Ética de la tierra, postula que se deben ampliar los límites de la comunidad para incluir suelos, aguas, plantas y animales, o, colectivamente, la tierra. En relación con lo que es ética y estéticamente correcto, defiende la siguiente máxima: "Algo es correcto cuando tiende a preservar la integridad, la estabilidad y la belleza de la comunidad biótica; y es incorrecto cuando tiende a lo contrario". Véase en: LEOPOLD, A., A Sand County Almanac, Oxford University Press, Londres, 1949.

${ }^{37}$ Arne Naess fue un académico noruego, considerado el padre de la "ecología profunda", un movimiento socioambiental que busca refundar los valores y estilos de vida de las sociedades actuales proponiendo una suerte de "igualitarismo ecológico" que tenga en cuenta el valor inherente de todos los seres de la biósfera. Una breve introducción al pensamiento de Arne Naess puede encontrarse en: SPERANZA, A., Ecología profunda y autorrealización. Introducción a la filosofía ecológica de Arne Naess, Biblos, Buenos Aires, 2006.

${ }^{38}$ Estos movimientos suelen diferenciarse, en razón de sus presupuestos, principios y objetivos, entre ecologistas/ambientalistas y animalistas. Véase en: FARIA, C., "Muerte entre las flores: el conflicto entre el ecologismo y la defensa de los animales no humanos", Viento Sur, núm. 125, 2012, pp. 67-76.
} 
humanos y los no humanos, mancomunados no sólo por una suerte incierta, sino también por la convergencia objetiva de los intereses por el futuro ${ }^{39}$.

Bajo otras perspectivas, "desde el Sur" se desarrollan un conjunto de discursos, prácticas e instituciones que han sido agrupados bajo la noción de "Buen Vivir" Sumak Kawsay en quechua $^{40}$, Suma Qamaña en aymara ${ }^{41}$, y que recogen planteamientos que provienen de "formas de vidas" de las poblaciones indígenas ancestrales y afrolatinoamericanas cuyo contenido da cuenta de una forma "armónica" de relación entre los seres humanos y la naturaleza ${ }^{42}$.

Estos planteos, que han sido plasmados en la Constitución de la República del Ecuador de 2008, la Nueva Constitución Política del Estado Plurinacional de Bolivia de 2009 y las leyes bolivianas $N^{\circ} 71 / 2010$ de Derechos de la Madre Tierra y $N^{\circ} 300 / 2012$ de la Madre Tierra y Desarrollo Integral para Vivir Bien, permiten abrir nuevas perspectivas desde las cuales repensar el vínculo entre animales humanos y no humanos ${ }^{43}$.

Este conjunto heterogéneo de aportes presentan un aspecto en común: tienden a promover la desmercantilización de lo vivo, sea mediante la atribución de valor intrínseco a lo no humano ${ }^{44}$, sea promoviendo una visión cósmica de relación armónica entre la humanidad y la naturaleza. Este proceso encuentra, a su vez, una expresión

\footnotetext{
${ }^{39}$ POCAR, V., Los animales no humanos. Por una sociología de los derechos, Ad Hoc, Buenos Aires, 2013, p. 146

${ }^{40}$ El quechua es una familia de lenguas originaria de los Andes centrales; se habla en Argentina, Bolivia, Chile, Colombia, Ecuador y Perú.

${ }^{41}$ El aymara es una lengua originaria de los Andes centrales; se habla en Argentina, Chile, Bolivia y Perú. En estos dos últimos países ha sido reconocida constitucionalmente como "lengua oficial". La Constitución boliviana consagra, en su artículo 5 inciso I, que son "idiomas oficiales del Estado" el castellano y "todos los idiomas de las naciones y pueblos indígenas originarios campesinos, que son el aymara, araona, baure, bésiro, canichana, cavineño, cayubaba, chácobo, chimán, ese ejja, guaraní, guarasu'we, guarayu, itonama, leco, machajuyai-kallawaya, machineri, maropa, mojeño-trinitario, mojeño-ignaciano, moré, mosetén, movima, pacawara, puquina, quechua, sirionó, tacana, tapiete, toromona, uru-chipaya, weenhayek, yaminawa, yuki, yuracaré y zamuco". El artículo 48 de la Constitución peruana establece como idioma oficial el castellano y, "en las zonas donde predominen", el quechua, el aimara y las "demás lenguas aborígenes".
}

${ }^{42}$ CORTEZ, D., "La construcción social del 'Buen Vivir' (Sumak Kawsay) en Ecuador. Genealogía del diseño y gestión política de la vida”, Revista Aportes Andinos, Quito, 2011.

${ }^{43}$ Las normativas del Buen Vivir no se encuentran exentas de contradicciones, que surgen de la convivencia del esquema del derecho ambiental clásico, que se expresa en un conjunto de postulados que se refieren al desarrollo humano y la protección del ambiente en pos de las "generaciones presentes y futuras", donde se articulan nociones como "gestión" y "aprovechamiento racional de la fauna", con un enfoque ético alternativo al antropocentrismo que se manifiesta en el concepto de "armonía con la naturaleza" y en la consagración de los "derechos de la naturaleza".

${ }^{44}$ Otras expresiones utilizadas son "valor en sí mismo" y "valor inherente", las cuales no se encuentran exentas de controversias terminológicas. 
articuladora entre los aportes de la ética ambiental y el Buen Vivir en una novedosa manera de abordar y brindar respuestas a la cuestión ecológica: el reconocimiento de derechos a lo no humano ${ }^{45}$.

\section{El reconocimiento de derechos a lo no humano como expresión articuladora de las diferentes propuestas de desmercantilización}

Desde el ámbito más estrictamente jurídico también surgieron propuestas en sintonía con los nuevos paradigmas reseñados en el apartado anterior. En 1972 se publica un texto fundacional: “¿Los árboles deberían tener legitimidad procesal? Hacia un reconocimiento de los derechos legales de los objetos naturales", escrito por Christopher D. Stone, profesor de la Facultad de Derecho de la Universidad del Sur de California. El autor sintetiza su propuesta de la siguiente manera:

Estoy sugiriendo de manera bastante seria que se le otorguen derechos legales a los bosques, a los océanos, a los ríos y a los llamados "objetos naturales" que constituyen el medio ambiente. De hecho, propongo que el medio ambiente, como unidad, sea sujeto de derechos ${ }^{46}$.

Stone, si bien se limita a discutir el estatus jurídico de los "objetos" de la naturaleza de origen no animal, invita al lector a abordar las diferentes situaciones en las que el análisis es adecuado para conceder derechos a otras entidades, entre las cuales destaca los animales no humanos. De esta manera, sería viable considerar que el reconocimiento de derechos a "elementos naturales" o a la naturaleza como totalidad abre caminos — tanto éticos como jurídicos- hacia el reconocimiento de derechos a los animales no humanos ${ }^{47}$.

\footnotetext{
${ }^{45}$ Otra noción que podría articular estas respuestas fue introducida en el pensamiento jurídico francés por Marie-Angèle Hermitte, quien denomina droit du vivant a la parte del derecho que se refiere al mundo de "lo vivo". Véase en: BERROS, V., "Porque tienen derecho a existir': una introducción al debate ético sobre el derecho de los animales no humanos", Cafferatta, N. A. (dir.) y Terzi, S. (coor.), Derecho ambiental: dimensión social, Rubinzal-Culzoni, Santa Fe, 2015, pp. 83-113.

46 STONE, C., “¿Los árboles deberían tener legitimidad procesal? Hacia un reconocimiento de los derechos legales de los objetos naturales", Derecho ambiental y justicia social, Siglo del Hombre Editores, Universidad de los Andes, Bogotá, 2009, p. 148.

$47 \mathrm{Si}$ bien en este artículo nos limitamos a analizar los planteamientos que tienden a extender el reconocimiento de derechos subjetivos más allá de lo humano, desde el campo jurídico también se ha abordado la cuestión animal y ecológica en relación con la función protectora del derecho; desde esta última perspectiva ha surgido, por ejemplo, la propuesta de extender más allá de lo humano el ámbito de protección del derecho, es decir, una extensión del "paradigma garantista" que busca limitar la acumulación del poder no solo para salvaguardar la especie humana, sino también otros seres vivos o la
} 
No obstante, sería la Constitución ecuatoriana de 2008 la que ampliaría los horizontes desde los cuales pensar los derechos de lo no humano al consagrar, por primera vez en la historia, los "derechos de la naturaleza". Lo novedoso de esta reforma constitucional es que surge de las revalorizaciones de cosmovisiones opacadas por el pensamiento moderno, en especial las de los pueblos indígenas de la región, los cuales, si bien no se identificaban a sí mismos como biocéntricos, concebían una relación "armónica" entre lo humano y lo no humano que implicaba el reconocimiento de valores intrínsecos a la naturaleza $^{48}$.

El artículo 71 de la Constitución de la República del Ecuador reconoce el derecho de la naturaleza - o Pachamama- a que "se respete integralmente su existencia y el mantenimiento y regeneración de sus ciclos vitales, estructura, funciones y procesos evolutivos". Si bien el carácter holístico del primer párrafo del artículo 71 excluiría del reconocimiento a los animales no humanos, en el tercer párrafo se amplía la protección al establecerse la obligación del Estado de promover el respeto "a todos los elementos que forman un ecosistema”. El interrogante que deja latente este postulado es si la promoción de "respeto" lleva implícita el reconocimiento de derechos subjetivos o si se fundamenta en clave kantiana, es decir, como un "deber" indirecto que encuentra su razón en la sensibilidad humana ${ }^{49}$.

La Constitución Política del Estado Plurinacional de Bolivia, por su parte, establece en su artículo 33 el derecho humano a un ambiente sano, pero con un postulado novedoso que no aparece en otras constituciones modernas: el ejercicio de este derecho no solo debe permitir a los individuos y las colectividades de las presentes y futuras generaciones "desarrollarse de manera normal y permanente", sino también a "otros

naturaleza en su totalidad. Véase en: GARCÍA SAEZ, J. A., “¿Pueden los animales ser titulares de derechos? Algunos argumentos desde una teoría garantista del Derecho", Revista Catalana de Dret Ambiental, vol. 3, núm. 2, 2012, pp. 1-23.

48 GUDYNAS, E., "La senda biocéntrica: valores intrínsecos, derechos de la naturaleza y justicia ecológica”, Tabula Rasa, núm. 13, Bogotá, 2010, pp. 45-71.

${ }^{49}$ Immanuel Kant, en sus Lecciones de ética — dictadas entre los años 1775 y 1781 -, considera que la humanidad no tiene ningún deber directo, de modo inmediato, para con los animales, sino que estos representan deberes indirectos para con la humanidad, ya que solamente el "hombre", como "criatura racional", es fin en sí mismo, un fin para el cual todo lo demás resulta un medio. Esta idea se encuentra presente en aquellas propuestas que ven en el maltrato animal - y podría extenderse a otros seres- una relación con la violencia entre seres humanos; en este sentido se expresó Kant en sus Lecciones: "Se puede, pues, conocer el corazón humano a partir de su relación con los animales". Véase en: KANT, I., Lecciones de ética, Crítica, Barcelona, 1988, p. 288. 
seres vivos". Este postulado es de raigambre biocéntrica y permitiría extender tal reconocimiento más allá de lo humano.

En el ordenamiento jurídico boliviano se encuentran, además, dos normas que conjugan el reconocimiento de valores intrínsecos a lo no humano con una apuesta por la desmercantilización de lo vivo: la Ley $N^{\circ} 71 / 2010$, de 21 de diciembre, de Derechos de la Madre Tierra y la Ley No 300/2012, de 15 de octubre, de la Madre Tierra y Desarrollo Integral para Vivir Bien. La primera tiene por objeto "reconocer los derechos de la Madre Tierra" (art. 1) ${ }^{50}$, que es definida como "el sistema viviente dinámico conformado por la comunidad indivisible de todos los sistemas de vida y los seres vivos, interrelacionados, interdependientes y complementarios, que comparten un destino común" (art. 3). Por su parte, en el artículo 2 inciso 5 fija, entre una serie de principios que rigen la Ley ${ }^{51}$, el de "no mercantilización”, según el cual "no pueden ser mercantilizados los sistemas de vida, ni los procesos que sustentan, ni formar parte del patrimonio privado de nadie" (art. 2 inc. 5). Este principio se reproduce, a su vez, en la Ley $N^{o} 300 / 2012$, que establece lo siguiente: "Las funciones ambientales y procesos

\footnotetext{
${ }^{50}$ Los derechos de la Madre Tierra se encuentran enumerados y detallados en el artículo 7 de la Ley $\mathrm{N}^{\circ}$ 71/2010: (1) a la vida, es decir, "al mantenimiento de la integridad de los sistemas de vida y los procesos naturales que los sustentan, así como las capacidades y condiciones para su regeneración”; (2) a la diversidad de la vida, que se manifiesta "en la preservación de la diferenciación y la variedad de los seres que componen la Madre Tierra, sin ser alterados genéticamente ni modificados en su estructura de manera artificial, de tal forma que se amenace su existencia, funcionamiento y potencial futuro"; (3) al agua, que consiste en "la preservación de la funcionalidad de los ciclos del agua, de su existencia en la cantidad y calidad necesarias para el sostenimiento de los sistemas de vida, y su protección frente a la contaminación para la reproducción de la vida de la Madre Tierra y todos sus componentes"; (4) al aire limpio, que se realiza en "la preservación de la calidad y composición del aire para el sostenimiento de los sistemas de vida y su protección frente a la contaminación, para la reproducción de la vida de la Madre Tierra y todos sus componentes"; (5) al equilibrio, definido como "el derecho al mantenimiento o restauración de la interrelación, interdependencia, complementariedad y funcionalidad de los componentes de la Madre Tierra, de forma equilibrada para la continuación de sus ciclos y la reproducción de sus procesos vitales"; (6) a la restauración "oportuna y efectiva de los sistemas de vida afectados por las actividades humanas directa o indirectamente"; (7) y, por último, a vivir libre de contaminación.

${ }^{51}$ Los principios que rigen la Ley No 71/2010 son: (1) "Armonía”, según el cual las actividades humanas "deben lograr equilibrios dinámicos con los ciclos y procesos inherentes a la Madre Tierra"; (2) "Bien Colectivo", que protege el interés de la sociedad por sobre toda actividad humana y por sobre cualquier derecho adquirido; (3) "Garantía de regeneración de la Madre Tierra", conforme al cual se "deben garantizar las condiciones necesarias para que los diversos sistemas de vida de la Madre Tierra puedan absorber daños, adaptarse a las perturbaciones, y regenerarse sin alterar significativamente sus características de estructura y funcionalidad, reconociendo que los sistemas de vida tienen límites en su capacidad de regenerarse, y que la humanidad tiene límites en su capacidad de revertir sus acciones"; (4) "Respeto y defensa de los Derechos de la Madre Tierra", que establece el deber del Estado y cualquier persona individual o colectiva de respetar, proteger y garantizar los derechos de la Madre Tierra para el Vivir Bien de las generaciones actuales y las futuras; (5) "No mercantilización"; y (6) "Interculturalidad", conforme al cual se requiere, para el ejercicio de los derechos consagrados, "del reconocimiento, recuperación, respeto, protección, y diálogo de la diversidad de sentires, valores, saberes, conocimientos, prácticas, habilidades, trascendencias, transformaciones, ciencias, tecnologías y normas, de todas las culturas del mundo que buscan convivir en armonía con la naturaleza”.
} 
naturales de los componentes y sistemas de vida de la Madre Tierra, no son considerados como mercancías sino como dones de la sagrada Madre Tierra" (art. 4 inc. 2).

La Ley $\mathrm{N}^{\circ} 71 / 2010$ establece, entre las obligaciones del Estado, la de "defender la Madre Tierra en el ámbito plurinacional e internacional de la sobreexplotación de sus componentes, de la mercantilización de los sistemas de vida o los procesos que los sustentan [...]" (art. 8 inc. 3). En consonancia con esto, la Ley N $\mathrm{N}^{\circ}$ 300/2012 establece, entre los deberes de la sociedad y las personas, el de promover "de forma sostenida y permanente procesos de desmercantilización de las relaciones entre los seres humanos y la naturaleza" (art. 11 inc. 3). Por último, dispone una serie de preceptos orientados a la no mercantilización del agua (art. 27 inc. 3) ni los bosques (art. 54 inc. I.2), así como una apuesta por excluir de los planes y programas de reducción de emisiones de gases de efecto invernadero los mecanismos de financiamiento asociados a los mercados de carbono (art. 32 inc. 5).

Estas propuestas, por impulso de ambientalistas y académicos, han comenzado a circular por otros países de la región. En Argentina, por ejemplo, el senador nacional Fernando Solanas presentó, a mediados del año 2015, un proyecto de ley sobre derechos de la naturaleza cuyo articulado conjuga los principios y derechos de la Madre Tierra establecidos en la Ley $N^{\circ} 71 / 2010$ de Bolivia con los derechos de la Pachamama consagrados en la Constitución ecuatoriana, si bien presenta algunas diferencias terminológicas, entre las cuales destaca la utilización de la palabra Naturaleza en lugar de Madre Tierra o Pachamama. El artículo 1 reproduce textualmente el primer párrafo del artículo 71 de la Constitución ecuatoriana, y el artículo 2 enumera los derechos de la naturaleza, teniendo como fuente los derechos y principios establecidos en los artículos 2 (principios) y 7 (derechos) de la Ley $\mathrm{N}^{\circ}$ 71/2010 de Bolivia: a la vida, a la diversidad de la vida, al agua, al aire limpio, al equilibrio, a la restauración y recomposición, a vivir libre de contaminación y a la no mercantilización. El tercer postulado reproduce el principio de "interculturalidad" de la Ley $\mathrm{N}^{\circ} 71$ de Bolivia, agregando un apartado novedoso: "Los procedimientos para la toma de decisiones que pudieren afectar los Derechos de la Naturaleza deberán dar cuenta de esta diversidad y generar los espacios 
institucionales de diálogo adecuados para fundar la decisión en base a la diversidad de saberes y prácticas en circulación" 52 .

Entre los fundamentos del proyecto argentino se plantea un pasaje desde "un paradigma antropocéntrico a otro de carácter sociobiocéntrico", sugiriendo una concepción de la naturaleza que abandone la idea de naturaleza como objeto desde una "perspectiva ética alternativa, al aceptar valores intrínsecos en el entorno", para lo cual se propone impulsar nuevas instituciones jurídicas, nuevos sujetos de derecho y nuevos mecanismos de toma de decisiones colectivas. Se afirma, en sintonía, que "[t]odos los seres tienen un valor, aun cuando no sean de utilidad para los humanos", lo que conlleva las siguientes consecuencias: (a) "la naturaleza como sujeto de derecho implica necesariamente su desmercantilización"53; (b) el paradigma de los derechos de la naturaleza reconoce valores intrínsecos de la naturaleza con independencia de la valoración humana; (c) el reconocimiento de la naturaleza como sujeto de derechos "exige una relación de igualdad y respeto entre los seres humanos y la misma", proponiéndose una noción de igualdad que trascienda lo humano; y (d) el reconocimiento de los derechos de la naturaleza precisa de otro campo de la justicia, la justicia ecológica, cuyo objetivo se enfocaría en "asegurar los procesos vitales" y no en las compensaciones económicas ${ }^{54}$.

\footnotetext{
${ }^{52}$ El principio de interculturalidad en el proyecto argentino no solo reconoce una "ecología de saberes", es decir, que "no sólo hay muy diversas formas de conocimiento de la materia, la sociedad, la vida y el espíritu sino también muchos y muy diversos conceptos de lo que cuenta como conocimiento y de los criterios que pueden ser usados para validarlo", sino que también impulsa el diseño de instituciones que logren canalizar esta diversidad de saberes. Véase en: SANTOS, B., Para descolonizar Occidente. Más allá del pensamiento abismal, CLACSO, Prometeo Libros, Buenos Aires, 2010.

${ }^{53}$ A diferencia de las normativas bolivianas y ecuatorianas, el proyecto argentino caracteriza la "no mercantilización" aclarando que "no es un obstáculo para el desarrollo y comercialización [...] de actividades agrícola-ganaderas". En este sentido, entre los fundamentos del proyecto se propone un ejemplo: mercantilización sería "financiarizar", es decir, incluir en el mercado financiero, la polinización que realizan las abejas; no las abejas como individuo, no la miel o los panales, sino "el acto de polinización". Esto guarda relación con el concepto de "sistemas de vida", que si bien es mencionado en los fundamentos del proyecto argentino, no ha sido definido en su articulado, lo cual nos remite a la Ley $\mathrm{N}^{\circ} 71 / 2010$ de Bolivia: "Son comunidades complejas y dinámicas de plantas, animales, micro organismos y otros seres y su entorno, donde interactúan comunidades humanas y el resto de la naturaleza como una unidad funcional, bajo la influencia de factores climáticos, fisiográficos y geológicos, así como de las prácticas productivas, y la diversidad cultural de las bolivianas y los bolivianos, y las cosmovisiones de las naciones y pueblos indígenas originarios campesinos, las comunidades interculturales y afrobolivianas" (art. 4).

${ }^{54}$ La justicia ecológica no excluye la justicia ambiental - es decir, la tutela del derecho a un ambiente sano-, como esta no excluye, a su vez, la justicia social; se propone la conjunción entre los derechos humanos y los derechos de la naturaleza bajo el amparo de tres ámbitos de la justicia diferenciados pero complementarios: la justicia social, la justicia ambiental y la justicia ecológica.
} 
Del conjunto de normativas analizadas surge una incipiente articulación entre un programa de desmercantilización y el reconocimiento de derechos a la naturaleza, la cual se identifica, también, como Pachamama o Madre Tierra ${ }^{55}$. Un reconocimiento que, si bien guarda estrecha relación con la historia de países andinos, configura una apuesta global que se corresponde con una concepción de la naturaleza en términos de un "patrimonio común de todos los seres vivos existentes" $"$.

\section{ALGUNAS REFLEXIONES FINALES}

Este artículo ha permitido visibilizar, aunque sea brevemente, la existencia de un conjunto amplio y heterogéneo de respuestas elaboradas frente al creciente comercio de animales no humanos que responden, a su vez, a diferentes concepciones en torno a conceptos tales como animal, humano, naturaleza, ciencia, objeto, sujeto...

Se han identificado dos programas. El primero, articulado con la protección mediante la regulación del comercio, se traduce en una serie de normativas que legislan sobre el comercio de la fauna, entre las cuales se considera medular la CITES; la perspectiva ética antropocéntrica permea estas regulaciones, que se caracterizan por reproducir el esquema del animal no humano como "cosa". El segundo programa ha permitido enlazar los aportes provenientes tanto "desde el Norte" como "desde el Sur" que proporcionan una serie de elementos relevantes para repensar la cuestión animal. En este sentido, se han analizado novedosos instrumentos jurídicos que traducen perspectivas de otras cosmovisiones en articulación con éticas y prácticas que abordan la problemática desde la desmercantilización; entre dichos instrumentos adquiere especial relevancia el reconocimiento de derechos a lo no humano.

\footnotetext{
${ }^{55}$ Este tipo de reconocimiento no está exento de críticas en relación con su efectividad en un contexto de políticas neoextractivistas como las implementadas por los gobiernos de Rafael Correa en Ecuador y de Evo Morales en Bolivia. Véase en: GUDYNAS, E., "Los derechos de la naturaleza en serio. Respuestas y aportes desde la ecología política", La naturaleza con derechos. De la filosofía a la política, Abya Yala, Universidad Politécnica Salesiana, Quito, 2010, pp. 239-286.

${ }^{56}$ Morales, Evo. (2012, 21 de junio). El ambientalismo del capitalismo es el nuevo colonialismo. Discurso de Evo Morales Ayma, Presidente del Estado Plurinacional de Bolivia, en Plenaria de la Conferencia de Naciones Unidas sobre Desarrollo Sostenible Río+20. Recuperado el 18 de enero de 2016,

$<$ http://www.comunicacion.gob.bo/sites/default/files/media/publicaciones/N\%C2\%B0\%205\%20-

\%20RIO\%2020.pdf $>$. Un abordaje multidimensional y multiescalar de las propuestas del Buen Vivir puede encontrase en: HAIDAR, V. y BERROS, V., "Hacia un abordaje multidimensional y multiescalar de la cuestión ecológica: la perspectiva del buen vivir", Revista Crítica de Ciências Sociais, núm. 108, 2015, pp. 111-134.
} 
Este ejercicio por/para develar los discursos y la diversidad de cosmovisiones, prácticas y saberes subyacentes a ambos programas se ha intentado con el objetivo de contribuir a colocar el derecho en diálogo con otros campos disciplinarios como la ética o los estudios sociales de la ciencia, entre otros, así como para colaborar en la revisión y reconstrucción de mecanismos jurídico-institucionales y de políticas públicas tendientes a abordar la apremiante problemática de la extinción de especies de animales no humanos.

En este sentido, el reconocimiento de derechos a lo no humano, en conjunción con una apuesta por la desmercantilización de lo vivo, abre nuevos horizontes al pensamiento jurídico ambiental. La sobreexplotación de la naturaleza ha tenido entre sus principales consecuencias la pérdida de la diversidad biológica, lo que ha brindado argumentos estadísticos para que desde la biología se comience a hablar de la era de "defaunación del antropoceno" y de los inicios de la "sexta extinción masiva" ${ }^{\text {"57 }}$. Como respuesta a esta problemática, desde diferentes disciplinas — biología, derecho, sociología - se propone no una "naturaleza intocada", sino una relación armónica entre sus distintos elementos desde un enfoque ético no antropocéntrico.

Esta relación armónica encuentra respaldo en dos procesos que han sido reseñados en este trabajo. En primer lugar, el reconocimiento de derechos a lo no humano, que en algunos países europeos se ha manifestado en una serie de reformas legislativas en torno al estatuto jurídico de los animales ${ }^{58}$, mientras que en América Latina se ha expresado mediante la consagración de los derechos de la naturaleza. En segundo lugar, la desmercantilización de lo vivo, que engloba, por una parte, las propuestas de extender el ámbito de consideración moral más allá de lo humano y, por otra, las alternativas de no mercantilización que surgen de la legislación boliviana en relación con las "funciones ambientales" y los "procesos naturales" de los sistemas de vida.

De esta manera, tanto el reconocimiento de derechos a lo no humano como los procesos de desmercantilización de lo vivo comparten un fundamento ético y un respaldo jurídico: el concepto moral de valor intrínseco y el surgimiento de nuevos sujetos de

${ }^{57}$ DIRZO, R., YOUNG, H. S., GAletTI, M., CEBAllos, G., ISAAC, N. J. B. y COLLEN, B., "Defaunation in the Anthropocene", Science, vol. 345, núm. 6185, 2014, pp. 401-406.

58 Estas propuestas adquirieron relevancia internacional mediante la aprobación de la Declaración Universal de los Derechos de los Animales por la Organización de las Naciones Unidas (ONU). Véase en: Liga Internacional de los Derechos del Animal. (1978, 15 de octubre). Declaración Universal de los Derechos de los Animales. Recuperado el 24 de abril de 2016, de http://www.me.gov.ar/efeme/diaanimal/derecho.html. 
derechos. A su vez, los aportes latinoamericanos se caracterizan por acentuar conceptos como diversidad o interrelación que integran la idea de "sistema de vida", lo que permite un abordaje más complejo que el mero otorgamiento de derechos a determinados seres vivos.

Así, la histórica tensión entre la satisfacción de las necesidades humanas y la protección de la naturaleza encuentra nuevas perspectivas en la defensa de los sistemas de vida desde un sentido holístico, donde conceptos como ecosistema o comunidad, entre otros, readquieren relevancia bajo una idea "extensa" de igualdad, una idea de igualdad que trasciende lo humano e involucra también la naturaleza. Bajo este esquema, la consagración de derechos a lo no humano en una apuesta por la desmercantilización de lo vivo se configura como el instrumento jurídico por excelencia en la efectivización de este nuevo contenido de la igualdad.

\section{REFERENCIAS BIBLIOGRÁFICAS}

\section{Libros}

BRAILOVSKY, A. y FOGUELMAN, D., Memoria verde. Historia ecológica de la Argentina, Debolsillo, Buenos Aires, 2013.

ESQUIVEL FRÍAS, L., Responsabilidad y sostenibilidad ecológica. Una ética para la vida, Facultad de Filosofía y Letras, Universidad Autónoma de Barcelona, 2006.

FRANCIONE, G., Animals, Property, and the Law, Temple University Press, Philadelphia, 1995.

KANT, I., Lecciones de ética, Crítica, Barcelona, 2002.

LATOUCHE, S., Limite, Adriana Hidalgo editora, Buenos Aires, 2014.

LATOUR, B., Nous n'avons jamais été modernes. Essai d'anthropologie symétrique, La Decouverte, París, 1997.

LEOPOLD, A., A Sand County Almanac, Oxford University Press, Londres, 1949.

PESTRE, D., Introduction aux science studies, La Découverte, París, 2006.

POCAR, V., Los animales no humanos. Por una sociología de los derechos, Ad Hoc, Buenos Aires, 2013. 
REGAN, T., The case for animals rights, University of California Press, California, 2004.

RÈMOND-GOUILLOUD, M., El derecho a destruir. Ensayo sobre el derecho del medio ambiente, Losada, Buenos Aires, 1994.

RIECHMANN, J. y MOSTERIN, J., Animales y ciudadanos, Talasa, Madrid, 1995.

SANTOS, B., Para descolonizar Occidente. Más allá del pensamiento abismal, CLACSO, Prometeo Libros, Buenos Aires, 2010.

SINGER, P., Liberación animal, Trotta, Madrid, 1999.

SPERANZA, A., Ecología profunda y autorrealización. Introducción a la filosofía ecológica de Arne Naess, Biblos, Buenos Aires, 2006.

WIJNSTEKERS, W., The Evolution of CITES, $9^{\mathrm{a}}$ ed., International Council for Game and Wildlife Conservation, 2011.

\section{Capítulos de libros}

BERROS, V., “'Porque tienen derecho a existir': una introducción al debate ético sobre el derecho de los animales no humanos", Cafferatta, N. A. (dir.) y Terzi, S. (coor.), Derecho ambiental: dimensión social, Rubinzal-Culzoni, Santa Fe, 2015, pp. 83-113.

GIMÉNEZ-CANDELA, T., "Estatuto jurídico de los animales: aspectos comparados", Baltasar, B. (coord.), El derecho de los animales, Marcial Pons, Madrid, 2015, pp. 149184.

GUDYNAS, E., "Los derechos de la naturaleza en serio. Respuestas y aportes desde la ecología política", La naturaleza con derechos. De la filosofía a la política, Abya Yala, Universidad Politécnica Salesiana, Quito, 2010, pp. 239-286.

STONE, C., “¿Los árboles deberían tener legitimidad procesal? Hacia un reconocimiento de los derechos legales de los objetos naturales", Derecho ambiental y justicia social, Siglo del Hombre Editores, Universidad de los Andes, Bogotá, 2009, pp. 135-230.

\section{Artículos de revista}


BERROS, V., "Breve contextualización de la reciente sentencia sobre el habeas corpus en favor de la orangutana Sandra: entre ética animal y derecho", Revista de Derecho Ambiental, núm. 41, Abeledo-Perrot, Buenos Aires, 2015.

BERROS, V., "El estatuto jurídico de la naturaleza en debate (meulen en el mundo del derecho)", Revista de Derecho Ambiental, núm. 36, Abeledo-Perrot, Buenos Aires, 2013.

CORTEZ, D., “La construcción social del 'Buen Vivir' (Sumak Kawsay) en Ecuador. Genealogía del diseño y gestión política de la vida", Revista Aportes Andinos, Quito, 2011.

DIRZO, R., YOUNG, H. S., GAlETTI, M., CEBAlloS, G., ISAAC, N. J. B. у COLLEN, B., "Defaunation in the Anthropocene", Science, vol. 345, núm. 6185, 2014, pp. 401-406.

FARIA, C., "Muerte entre las flores: el conflicto entre el ecologismo y la defensa de los animales no humanos", Viento Sur, núm. 125, 2012, pp. 67-76.

GARCÍA SAEZ, J. A., “¿Pueden los animales ser titulares de derechos? Algunos argumentos desde una teoría garantista del Derecho", Revista Catalana de Dret Ambiental, vol. 3, núm. 2, 2012, pp. 1-23.

GONZÁLEZ RUIZ, E., “Ejecución de la Convención sobre el Comercio Internacional de Especies Amenazadas de Fauna y Flora Silvestres (CITES) en la República Argentina", Ambiente y Recursos Naturales. Revista de Derecho, Política y Administración, vol. 2, núm. 1, La Ley, Buenos Aires, 1985, pp. 19-25.

GUDYNAS, E., "Concepciones de la naturaleza y desarrollo en América Latina", Persona y Sociedad, vol. 13, núm. 1, 1999, pp. 101-125.

GUDYNAS, E., "La senda biocéntrica: valores intrínsecos, derechos de la naturaleza y justicia ecológica", Tabula Rasa, núm. 13, Bogotá, 2010, pp. 45-71.

HAIDAR, V. y BERROS, V., "Entre el 'sumak kawsay' y la 'vida en armonía con la naturaleza': disputas en la circulación y traducción de perspectivas respecto de la regulación de la cuestión ecológica en el espacio global”, Revista Theomai Estudios Críticos sobre Sociedad y Desarrollo, año 15, núm. 32, Buenos Aires, 2014, pp. 128155. 
HAIDAR, V. y BERROS, V., "Hacia un abordaje multidimensional y multiescalar de la cuestión ecológica: la perspectiva del buen vivir", Revista Crítica de Ciências Sociais, núm. 108, 2015, pp. 111-134.

HOUTART, F., "El concepto de Sumak Kawsai y su correspondencia con el bien común de la humanidad”, América Latina en Movimiento, 2011, pp. 1-20.

KAKABADSE, Y., "Carta Magna para la vida silvestre”, Conservación Mundial. El comercio de especies. La CITES en el nuevo milenio, vol. 33, núm. 3, 2002, p. 3.

MENGUI, O., “CITES: Un acuerdo de importancia capital para la conservación de la fauna y flora mundiales", Ambiente y Recursos Naturales. Revista de Derecho, Política y Administración, vol. 1, núm. 2, La Ley, Buenos Aires, 1985, pp. 11-14.

UNCETA, K., "Poscrecimiento, desmercantilización y 'buen vivir"”, Nueva Sociedad, núm. 252, 2014, pp. 136-152.

\section{Documentos}

Conferencia Mundial de los Pueblos sobre el Cambio Climático y los Derechos de la Madre Tierra. (2010, 24 de abril). Declaración Universal de los Derechos de la Madre Tierra. Recuperado el 12 de enero de 2016, de http://rio20.net/propuestas/declaracionuniversal-de-los-derechos-de-la-madre-tierra/.

Convención sobre el Comercio Internacional de Especies Amenazadas de Fauna y Flora Silvestres. (2003, 3 de marzo). CITES en el Mundo. Boletín Oficial de las Partes. Recuperado el 28 de noviembre de 2015, de https://www.cites.org/sites/default/files/esp/news/world/30special.pdf.

Convención sobre el Comercio Internacional de Especies Amenazadas de Fauna y Flora Silvestres. (2013, 14 de marzo). XVI Reunión de la Conferencia de Partes. Resolución Conf. 16.3. Visión Estratégica de la CITES: 2008-2020. Recuperado el 8 de agosto de 2015, de http://www.cites.org/esp/res/16/16-03.

Convention on Biological Diversity. (2010, 29 de octubre). Tenth meeting of the Conference of the Parties. Aichi Biodiversity Targets. Recuperado el 18 de enero de 2016, de https:/www.cbd.int/sp/targets/. 
International Union for Conservation of Nature. The IUCN Red List of Threatened Species. Versión 2015-4. Recuperado el 17 de noviembre de 2016, de http://www.iucnredlist.org.

Liga Internacional de los Derechos del Animal. (1978, 15 de octubre). Declaración Universal de los Derechos de los Animales. Recuperado el 24 de abril de 2016, de http://www.me.gov.ar/efeme/diaanimal/derecho.html.

Morales, Evo. (2012, 21 de junio). El ambientalismo del capitalismo es el nuevo colonialismo. Discurso de Evo Morales Ayma, Presidente del Estado Plurinacional de Bolivia, en Plenaria de la Conferencia de Naciones Unidas sobre Desarrollo Sostenible Río+20. Recuperado el 18 de enero de 2016, de http://www.comunicacion.gob.bo/sites/default/files/media/publicaciones/N\%C2\%B0\%2 05\%20-\%20RIO\%2020.pdf.

Naciones Unidas. (1972, 16 de junio). Declaración de la Conferencia de las Naciones Unidas sobre el Medio Humano. Recuperado el 18 de noviembre de 2015, de http://www.ambiente.gov.ar/infotecaea/descargas/estocolmo01.pdf.

Naciones Unidas. (2010, 20 de diciembre). Resolución 65/164. Armonía con la naturaleza. Recuperado el 12 de noviembre de 2015, de http://www.un.org/en/ga/search/view_doc.asp?symbol=A/RES/65/164\&Lang=S.

Naciones Unidas. (2012, 22 de junio). Conferencia de las Naciones Unidas sobre el Desarrollo Sostenible Río+20. El futuro que queremos. Recuperado el 12 de noviembre de 2015, de https://rio20.un.org/sites/rio20.un.org/files/a-conf.216-1-1_spanish.pdf.pdf.

World Wildlife Fund et ál. Living Planet. Report 2014. Species and spaces, people and places. Recuperado el 18 de diciembre de 2015, de http://www.worldwildlife.org/pages/living-planet-report-2014. 